\title{
Empirical Analysis on the Relation Between Electronic Industry Development and Energy Consumption
}

\author{
Yu Mengdi* \\ College of Economy and Management,Nanjing University \\ of Aeronautic and Astronautic, \\ Nanjing 210016, China
}

\begin{abstract}
Data from 1996 to 2012 is used to conduct co-integration test, VAR model and Granger causality test in order to examine the relation between China's electronic industry added-value and energy consumption. The result of co-integration test illustrates the long-term equilibrium of the relationship between the electronic industry development and energy consumption. The dynamic analysis of VAR model shows that there is a positive response from the economic growth of the electronics industry to energy consumption, while the impact of energy consumption on economic growth is a slightly negative response. It has been proved that the electronic industry development and energy consumption are mutual Granger causality. According to these conclusions, some suggestions are proposed in the end, including accelerating the development of China's electronic industry to promote high-tech electronic products, improving energy efficiency, enhancing research efficacy, creasing the effort for energy development and implementing rational energy policies.
\end{abstract}

Kevwords-electronic industry, energy consumption, vector auto-regression, China.

\section{INTRODUCTION}

With the rapid economic growth led by electronic industry, the demand and consumption of energy resources are also on the rise. Since the reform and opening-up, scholars at home and abroad have been researching empirically on the relation between energy consumption and economic growth; however, there is little research studying about the relation between electronic industry evolution and energy consumption in China. Whether it is the rush development of electronic industry leads to the increase of energy consumption or the energy consumption promotes electronic industry evolution is a hot issue being discussed by the academic and business circles.

Bengal's GDP growth has a unidirectional impact on the rise of electricity consumption in that region manifested by foreigner scholar Mozumber. ${ }^{[1]}$ Lee, Mahadevan and other scholars studied deeply on the member states of G11 as well as several developed and developing countries; the result revealed a two-way causal relation between the economic growth and

\author{
Wang Zilong \\ College of Economy and Management,Nanjing University \\ of Aeronautic and Astronautic, \\ Nanjing 210016, China
}

energy consumption in these countries. ${ }^{[2,3]}$ Ghali and his colleagues used Johansen method and found out a two-way causality between Canada's production growth and energy consumption. ${ }^{[4]}$ The statistics of 79 countries from 1989 2007 was utilized by K.Ali Akkemik and Ky Goksal to disclose the fact that 7/10 of these countries had a two-way causality between energy consumption and economic growth, 2/10 had no Granger causality and $1 / 10$ had a unidirectional causality. ${ }^{[5]}$ Domestic scholar Huimin Zhang, utilizing co-integration theory, the decomposition of indices and log linear function, revealed a positive two-way causal relation between energy consumption and economic growth in Jilin province. ${ }^{[6]}$ According to the study of Qiongwei Yan and Hao Chen, there is less than causality between energy consumption and economic growth in China. Because of the special condition and different researching period in China, the result is far from the conclusion given by domestic and foreign scholars. ${ }^{[7]}$

Combining the research results from domestic and foreign scholars, it can be shown that relevant studies largely depend on macroeconomic perspective to analyze the relation between energy consumption and economic growth as a whole, and the conclusions are vary due to different regions' statistics and time series.

\section{EMPIRICAL ANALYSES ON ELECTRONIC INDUSTRY EVOLUTION AND ENERGY CONSUMPTION}

1996 2013 was an overridingly important period for the transition of market economy in China as well as a significant period for the implementation of national "10th five-year plan" and "11th five-year plan" and a critical moment for the conduct of "12th five-year plan". As China is moving forward to a moderately prosperous society in all dimensions, consumption level is turning into a continuously upgrading stage, the demand of electronic products is growing up dramatically which will undoubtedly improve the development of electronic industry. Total output value of China's electronic industry was 82.695 billion in 
1996 and increased to 2293.186 billion in 2014 with an annual growth rate of $20.27 \%$. The growth of electronic industry added-value was quite considerable with an annual growth rate of $20 \%$. In 2000 , the annual growth rate reached a peak of $41.25 \%$. After that, electronic industry added-value gradually climbed and achieved 1140.786 billion in 2008 which was a breakthrough. In the past decades, electronic industry still maintained a powerful momentum without a falling added-value even though the annual growth rate was far from notable. Electronic industry added-value reached 2043.838 billion in 2013, doubled the figure of 2008 in a short period. Although the annual growth rate was $12.2 \%$ in 2014 , electronic industry added-value achieved its highest point in these years which was 2293.186 billion. Assimilate into WTO stimulates the rapid development of electronic industry in China.

In the past decade, energy consumption in China had been increasing step by step. In 1996, energy consumption was 135,192 tons of standard coal and in 2013, energy consumption was 375,000 tons of standard coal. The annual growth rate was $5.83 \%$. In term of electronic industry, energy consumption increased from 371.38 tons of standard coal in 1996 to 2,666.75 tons of standard coal in 2012 with an annual growth rate of $12.3 \%$. In contrast, electronic industry added-value growth rate was slightly higher than energy consumption growth rate. As for electronic industry, energy consumption is mainly electricity consumption, and coal consumption ranks the second. China is still an industrial-based country, and electronic industry mainly depends on consuming electricity to research, develop and manufacture brand new electronics.

\section{A. Co-integration test}

E-G Two Step Method uses co-integrating regression method(OLS) to examine co-integrate relation among variables and assess co-integrating vector. On the basis of existing co-integration, put the residuals which are calculated in the first step into the error correction model as unbalanced errors and use OLS method to evaluate the corresponding parameters. Unit root test has been conducted before proceeding co-integration test, and shows that the time series of electronic industry added-value and energy consumption are second-ordered co-integrated which is the prerequisite to meet the co-integration test. Co-integration test should be conducting in two steps:

First step: conduct co-integrating regression.

Establish equation: .

Regression equation:
Residuals formula:

Second step: examine co-integration of $\varepsilon_{t}$. Conducted by Eviews8.0, the sequence of $\varepsilon_{t}$ has not have conspicuous trend of increasing as time goes by with the means of zero. Therefore, when conducting ADF test, constant terms and trends terms should not be involved. Through comparison, a variable lag of second order should be chosen. According to the result of unit root test of residuals sequence of $\varepsilon_{t}$, in $5 \%$ significant level, the absolute value of ADF is greater than the absolute value of threshold value due to $|-3.737728|>|-1.970978|$. Therefore, residuals sequence $\varepsilon_{\mathrm{t}}$ is considered to be stationary, which indicates that there exists long-term and stable balanced relation between electronic industry added-value and energy consumption.

\section{B. VAR model}

\section{a. Establishment of VAR model}

There is a link between economic growth and energy production and consumption which the traditional econometric models fail to explain. Compare to other econometric models, the largest characteristic of VAR model, proposed by Sims in 1980, is the adoption of simultaneous multi-equation form without strict economic theory as the basis. In each equation of VAR model, regression is conducted by endogenous variables on the lagging terms of all endogenous variables in order to estimate the dynamic relationship between all the endogenous variables. Logarithm of GVA and EC can be denoted as $\log (\mathrm{GVA})$ and $\log (\mathrm{EC})$. Establish vector autoregressive model with $\log (\mathrm{GVA})$ and $\log (\mathrm{EC})$ as endogenous variables. The lag selection standard of VAR model shows that out of 6 evaluation indexes indicate that VAR(4)should be established. So establish VAR(4)model:

Eviews 8.0 is used to inspect the stability of formula (2.6). Calculate AR root of the model and output the reciprocal of AR root. The result turns out that all the dots are located inside the unit circle, which indicates model(2.6)is stable.

\section{b. Impulse response analysis}

Impulse response function can be used to measure the impact of one standard deviation shock of a random disturbance on the endogenous variables' current and future value. According to the evaluated VAR(4)model, impulse response function diagram can be achieved as shown in figureland figure2. The horizontal axis represents the lag phases of impulse impact (unit: year), and the vertical axis represents corresponding variables; 
the solid line represents the impulse response function curves; dashed line indicates the deviation of plus or minus two standard deviations band. Due to the possibility of a long-term and balanced relation between electronic industry economic growth and energy consumption, the tracking installments of impulse response function are set up to be 20 years.

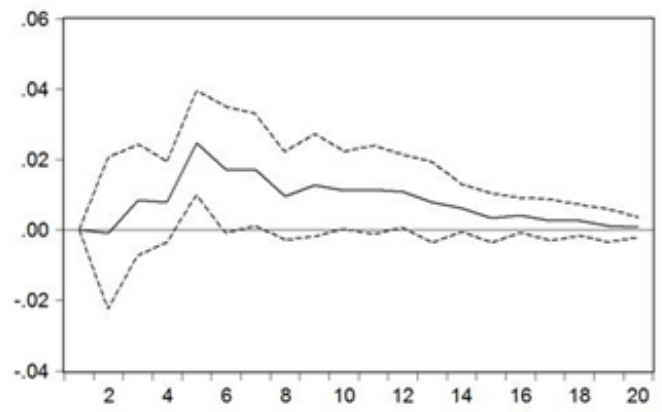

Figure1 Impulse response function diagram of $\log (G V A)$ to $\log (E C)$

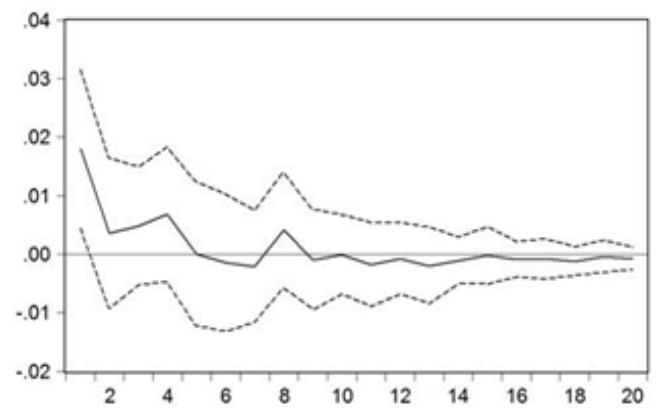

Figure2 Impulse response function diagram of $\log (E C)$ to $\log (G V A)$

Figure 1 and figure 2 are impulse response function diagrams of $\log (\mathrm{GVA})$ to $\log (\mathrm{EC})$ and $\log (\mathrm{EC})$ to $\log (\mathrm{GVA})$ respectively. As shown in figure 1, after a standard deviation impact on electronic industry energy consumption in this period, there will be a positive response of electronic industry economic growth which will increase rapidly in a short term, begin to decrease when reaching the peak after 5 years with a slow pace. Such kind of economic change will maintain until disappear in the 19th period. It illuminates that the growth of electronic industry energy consumption may not only promote economic development, but it also contains a medium- and long-term impact. The growth of electronic industry still relies largely on energy consumption.

As shown in figure2, after a standard deviation impact on electronic industry added-value in this period, there will be both positive and negative response of electronic industry energy consumption. The first 4 years will stay in a positive-response period with a little fluctuation which may lead to significant change in energy consumption. During the fifth to seventh year, negative response may occur, and again, positive response is going to generate. The curve inclines to zero in ninth year and afterwards. With the increasing demand of energy resources, market balance leads to rising price of energy resources, and the rising price of energy resources results in the declining demand of energy resources. When it comes to the ninth year, there will be a long-term and balanced relationship between electronic industry economic growth and energy consumption.

\section{Granger causality test}

Co-integration test of electronic industry evolution and energy consumption indicates a long-term and balanced relation. The equilibrium between them is the result of electronic industry energy consumption EC leads to the changes of electronic industry added-value GVA, or the result of electronic industry added-value GVA leads to the changes of electronic industry energy consumption EC? Granger causality test should be conducted on GVA and EC, results can be achieved through comparison.

Table 1:Granger causality test

\begin{tabular}{ccll}
\hline Hypothesis & Observations & F Statistic & Probability \\
\hline A & 16 & 3.68369 & 0.0772 \\
B & & 4.60637 & 0.0513 \\
A & 15 & 1.03329 & 0.3909 \\
B & & 2.27294 & 0.1536 \\
A & 14 & 0.9904 & 0.4508 \\
B & & 2.13511 & 0.1841 \\
\hline A & 13 & 4.24372 & 0.0952 \\
B & & 11.774 & 0.0174 \\
A & 12 & 1.68827 & 0.5237 \\
B & & 4.67818 & 0.3367 \\
\hline
\end{tabular}


*A: Granger causality does not exist from $E C$ to $G V A$ B: Granger causality does not exist from GVA to $E C$

As can be shown in table2, in the circumstances of first lag and forth lag, null hypothesis of Granger causality does not exist from EC to GVA and null hypothesis of Granger causality does not exist from GVA to EC will be both denied, which means the two-way Granger causality relation exists from economic growth to energy consumption and from energy consumption to economic growth in electronic industry.

\section{CONCLUSION}

This paper investigates into the industrial revolution and energy consumption of China's electronic industry. Through applying the electronic industrial energy consumption and economic database, together with various econometric models such as co-integration test and Granger causality test, the analysis of interactive relations between electronic industrial evolution and energy consumption reveals the following concluding remarks:

(1)Chinese electronic industry added-value and energy consumption presents an uprising trajectory. From 1996 to 2014, the added-value annual increase rate of electronic industry is $20.27 \%$. In 2008, the added-value unprecedentedly broke through the 1-trillion milestone, which skyrocketed to 2 trillion in 2013. From 1996-2012, the electronic industry energy consumption increase rate was $12.3 \%$, with primary percentage in electric and coal consumption.

(2)Chinese electronic industry added-value and energy consumption maintains a co-integration relationship. While in the short run, there have been fluctuations between the two; the long-term perspective reveals that the economic growth of electronic industry holds a long-term balanced relationship with energy consumption.

(3)The VAR model of Chinese electronic industry evolution and energy consumption reveals that they have a forth order VRA relationship. The impulse response shows that the evolution of the electronic industry relies heavily on the energy consumption, and a long-term balanced relationship is maintained between the two.

(4)The development of Chinese electronic industry is related with the energy consumption by Granger causal effect. The development of the electronic industry is a Granger cause of energy consumption. Following the development and economic growth of electronic industry, the energy consumption consequently increases with it. Moreover, the energy consumption of electronic industry is also a Granger cause of the industrial development. When the energy consumption rises, it pushes the electronic industry forward.

According to the abovementioned conclusions, this paper presents the following policy suggestions:

Firstly, the continuous supply of energy should be maintained in order to achieve a steady increase in electronic industry. As it is going to take China a considerable amount of time in the era of mid-industrialization, the demand of electronic products will continue to roar. The decline of the energy consumption of electronic industry will affect the development of the industry, while the economic growth of electronic industry will demand an increase in energy supply, which is why the energy supply should be ensured for electronic industry economic development.

Secondly, the research efficiency and the efficiency of energy consumption of the electronic industry should be increased with the development of advanced technologies. Aside from absorbing the advanced technologies from other countries, the domestic self-developed technologies should be enhanced in both quality and efficiency. The efficiency of R\&D process should be largely increased with more investment in advanced technologies and discarding of old facilities.

Last but not least, the policies in the system of energy pricing should be improved by adjusting energy strategy and energy policy. Concerned departments should implement policies that encourage energy reduction and recycling to ensure the continuous and sustainable growth of the electronic industry.

\section{References}

[1] Mozumder P, Achla M. Causality Relationship between Electricity Consumption and GDP in Bangladesh [J], Energy Policy, 2007, (35):95-402.

[2] Lee C. The Causality Relationship between Energy Consumption and GDP in G -11 Countries Revisited[J], Energy Policy, 2006, (34):1086-1093.

[3] Mahadevan R, Asafu-Adjaye J. Energy Consumption, Economic Growth and Prices: A Reassessment Using Panel VECM for Developed and Developing Countries[J], Energy Policy, 2007, 35: 2481-2490.

[4] Ghali K H, El-Sakka M I T. Energy Use and Output Growth in Canada: A Multivariate Co-integration Analysis [J], Energy Economics, 2004, (26):225-238.

[5] K.Ali Akkemik, Koray Goksal.Energy 
Consumption-GDP Nexus: Heterogeneous Panel Causality Analysis [J],Energy Economics, 865-873.

[6] Huimin Zhang, Qiang Wei, Lianjun Tong. Empirical Research on Industrial Development and Energy Consumption in Jilin Province [J],
Geographical Sciences, 2013, (12):68- 69.

[7] Qiongwei Yan, Hao Chen. Study on the Relationship between GDP and Energy Consumption [J], China Population. Resources and Environment, 2011, (7003-): 013. 